Relato de experiência

\title{
Função exponencial: uma estratégia didática aplicada no Ensino Médio
}

\author{
Exponential function: a didactic strategy applied in High School
}

Función exponencial: una estrategia didáctica aplicada en la Escuela Secundaria.

\author{
Cristiana Monique Feltes Sivert ${ }^{1}$ \\ [0000-0003-2711-8503] \\ Cassiano Scott Puhl ${ }^{2}$ \\ [0000-0003-0696-5666] \\ Elaine Corrêa Pereira ${ }^{3}$ \\ [0000-0002-3779-1403]
}

\begin{abstract}
Resumo
Este artigo apresenta o relato de experiência de uma estratégia didática aplicada em uma turma de primeiro ano de Ensino Médio de uma escola pública do interior do Rio Grande do Sul. A estratégia didática foi planejada considerando os pressupostos teóricos da Teoria de Aprendizagem Significativa de David Ausubel, cujo objetivo é tornar o aluno protagonista no processo de aprendizagem de conceitos e propriedades das funções exponenciais. Em busca desse objetivo, a estratégia didática foi organizada em seis etapas: questionário prévio para verificar subsunçores; atividade de dobradura de papel para introduzir o conceito de função exponencial; jogo da memória das propriedades de potência para ativar subsunçores; oficina de jogos para abordar conceitos mais específicos; situaçõesproblema sobre Matemática Financeira para contextualizar o ensino; e questionário avaliativo da estratégia didática. A partir do planejamento dessas etapas, se rompe com o ensino descontextualizado e meramente expositivo para promover a interação, a cooperação e compartilhamento de conhecimentos entre os alunos e/ou com o professor. Por fim, constatou-se que $80 \%$ dos alunos se envolveram ativamente nas atividades propostas, apresentando indícios de compreensão dos conceitos e propriedades da função exponencial, bem como a aplicabilidade no mundo real.
\end{abstract}

Palavras-chave: Função exponencial. Aprendizagem Significativa. Estratégia didática. Ensino médio.

\section{Abstract}

This article presents the experience report of a didactic strategy applied in a first year class of a public school in the interior of Rio Grande do Sul. The didactic strategy was planned considering the theoretical assumptions of the Significant Learning Theory of David Ausubel, whose objective is to make the student protagonist in the process of learning concepts and properties of exponential functions. In pursuit of this objective, the didactic strategy was organized in six stages: a previous

${ }^{1}$ cristianafeltes@hotmail.com, Especialista para Professores de Matemática pela Universidade Federal do Rio Grande, professora no Colégio Cenecista Frederico Michaelsen e Escola de Ensino Médio Capital do Saber, Bom Princípio/Rio Grande do Sul/Brasil.

2 c.s.puhl@hotmail.com, Mestre em Ensino de Ciência e Matemática pela Universidade de Caxias do Sul, doutorando do Programa de Pós-Graduação em Educação em Ciências e Matemática da Pontifícia Universidade Católica do Rio Grande do Sul, Porto Alegre/Rio Grande do Sul/Brasil.

${ }^{3}$ elainepereira@prolic.furg.br, Pós-Doutora pela Universidade Eduardo Mondlane, professora da Universidade Federal do Rio Grande, Rio Grande/Rio Grande do Sul/Brasil. 
questionnaire to verify subsunçores; paper folding activity to introduce the concept of exponential function; memory sets of power properties to activate subsumes; games workshop to address more specific concepts; problem situations on Financial Mathematics to contextualize teaching; and evaluation questionnaire of didactic strategy. From the planning of these stages, it breaks with decontextualized and merely expositive teaching to promote interaction, cooperation and sharing of knowledge between the students and / or the teacher. Finally, it was found that $80 \%$ of the students were actively involved in the proposed activities, presenting signs of understanding the concepts and properties of the exponential function, as well as the applicability in the real world.

Keywords: Exponential function. Significant Learning. Didactic strategy. High school.

\section{Resumen}

Este artículo presenta el informe de experiencia de una estrategia didáctica aplicada en una clase de primer año de una escuela pública en el interior de Rio Grande do Sul. La estrategia didáctica se planificó considerando los supuestos teóricos de la Teoría del Aprendizaje Significativo de David Ausubel, cuyo objetivo es hacer al alumno protagonista en el proceso de aprendizaje de conceptos y propiedades de funciones exponenciales. Para alcanzar este objetivo, la estrategia didáctica se organizó en seis etapas: un cuestionario previo para verificar subsunçores; actividad de plegado de papel para introducir el concepto de función exponencial; conjuntos de memoria de propiedades de energía para activar subsumes; taller de juegos para abordar conceptos más específicos; situaciones problemáticas en Matemática Financiera para contextualizar la enseñanza; y cuestionario de evaluación de estrategia didáctica. A partir de la planificación de estas etapas, se rompe con una enseñanza descontextualizada y meramente expositiva para promover la interacción, la cooperación y el intercambio de conocimientos entre los estudiantes y / o el profesor. Finalmente, se descubrió que el $80 \%$ de los estudiantes participaron activamente en las actividades propuestas, presentando signos de comprensión de los conceptos y propiedades de la función exponencial, así como la aplicabilidad en el mundo real.

Palabras claves: Funcion exponencial. Aprendizaje significativo. Estrategia didáctica. Escuela secundaria.

\section{Introdução}

O contexto educacional tem mostrado fortes indícios que, em sua maioria, os conhecimentos matemáticos são ensinados de uma forma teórica e descontextualizada, dificultando o envolvimento do aluno no processo de aprendizagem. O predomínio de um ensino descontextualizado dos conhecimentos matemáticos e da física é notório em qualquer nível de ensino que enfatiza a memorização de fórmulas matemáticas e algoritmos de resolução (SANTOS, 2004; SILVA; SALES; CASTRO, 2019). Nessa perspectiva, dificilmente se proporcionará a construção de significados, fazendo com que os alunos compreendam que os conhecimentos matemáticos se reduzem à fórmulas para serem aplicadas em determinadas situações (SOARES; SAUER, 2004; VARRIALE; TREVISAN, 2012).

Complementando, Pontes (2018) argumenta que ensino de Matemática na Educação Básica está passando por um processo de transformação, no qual as estratégias didáticas planejadas pelos professores estão buscando tornar os estudantes protagonistas no processo de aprendizagem. O ensino e o professor de Matemática da Educação Básica precisam se readequar ao mundo tecnológico, desenvolvendo capacidade e habilidades para formar cidadãos para suprirem as necessidades do mundo moderno (PONTES, 2018). 
Em busca de romper com esse cenário, neste trabalho, apresenta-se uma estratégia didática, fundamentada nos pressupostos teóricos da Teoria da Aprendizagem Significativa de David Paul Ausubel ${ }^{4}$, que busca promover o envolvimento de alunos do Ensino Médio na compreensão dos conceitos e propriedades das funções exponenciais. Por meio de atividades interativas e investigativas pretende-se qualificar os processos de ensino e de aprendizagem, além de motivar os alunos a aprofundarem seus conhecimentos na área da Matemática (BOOTH et al., 2016).

O objetivo deste trabalho é verificar as aprendizagens desenvolvidas de conceitos e propriedades das funções exponenciais por meio de uma estratégia didática que busca tornar o aluno protagonista no processo de aprendizagem. A partir dos conhecimentos prévios dos alunos pretende-se estabelecer relações com os conteúdos abordados na estratégia didática, construindo significados e não apenas memorizando algoritmos ou fórmulas matemáticas. A seguir, descrevem-se os pressupostos teóricos que fundamentam este trabalho.

\section{Pressupostos teóricos}

O predomínio das aulas meramente expositivas implica na passividade do aluno no processo de aprendizagem, tornando-as monótonas e rotineiras - ouvir ao professor, copiar os conteúdos didáticos, memorizá-los e replicá-los em exercícios e avaliações (GALIAZZI, 2003; DEMO, 2011). Um indicativo do predomínio desse contexto escolar está nos resultados de avaliações nacionais e internacionais como, por exemplo, o Sistema Nacional de Avaliação da Educação Básica (SAEB) e o Programa Internacional de Avaliação de Estudantes (PISA). Por meio dessas avaliações é possível constatar "[...] certo descontentamento em torno da aprendizagem em Matemática, por parte dos alunos, e do ensino, por parte dos professores [...]" (PACHECO; ANDREIS, 2018, p. 106).

Considerando essa perspectiva de sala de aula, predomina-se um ensino descontextualizado e disciplinar, desestimulando o aluno a construir significados e dificultando o estabelecimento de relações entre os conhecimentos matemáticos com situações contextualizadas (D'AMBROSIO, 1997, 2011), propiciando uma aprendizagem mecânica ${ }^{5}$. Contrapondo esse contexto, podem-se abordar os conhecimentos matemáticos de forma contextualizada, pois possibilita

Fazer matemática, resolvendo problemas, através de materiais manipulativos, de diferentes tecnologias ou de modelagem matemática, tem como consequência, além da aprendizagem de conteúdos matemáticos interligados aos de outras ciências, a estruturação da maneira de pensar e agir do indivíduo. (SANTOS, 2004, p. 5).

\footnotetext{
${ }^{4}$ David Paul Ausubel (1918-2008) é descendente de família judaica, nasceu em Nova lorque e tornou-se doutor em psicologia do desenvolvimento pela Columbia University. Ausubel publicou livros, sobre temas diversos, tais como: psicologia do desenvolvimento e da educação; dependência de drogas; psicopatologia e desenvolvimento do ego (DAVID P. AUSUBEL, 2019). Em relação aos estudos voltados para a área da Educação, destaca o desenvolvimento da Teoria de Aprendizagem Significativa que é abordado, principalmente, em duas obras: Psicologia Educacional (1968) e Aquisição e retenção de conhecimentos: uma perspectiva cognitiva (2003).

${ }^{5}$ A aprendizagem mecânica é definida como a "aquisição de associações arbitrárias literais em situações de aprendizagem nas quais o próprio material de aprendizagem não pode ser relacionado não arbitrariamente ou substantivamente à estrutura cognitiva (isto é, não possui "significado lógico") ou no qual o aprendiz apresenta uma disposição para uma aprendizagem não significativa” (AUSUBEL; NOVAK; HANESIAN, 1980, p. 521).
} 
O ensino contextualizado permite que o aluno estabeleça relações entre experiências prévias e o conteúdo da tarefa de aprendizagem, qualificando o processo de ensino e possibilitando uma aprendizagem significativa. A aprendizagem significativa

Consiste no fato de que novas ideias expressas de forma simbólica (a tarefa de aprendizagem) se relacionam àquilo que o aprendiz já sabe (a estrutura cognitiva deste numa determinada área de matérias), de forma não arbitrária e não literal, e que o produto desta interação ativa e integradora é o surgimento de um novo significado, que reflete a natureza substantiva e denotativa deste produto interativo. (AUSUBEL, 2003, p. 71).

Desse modo, a aprendizagem significativa ocorre quando o aluno possui e utiliza conhecimentos prévios, como apoio, para ancorar um novo conhecimento na sua estrutura cognitiva. Nesse processo de ancoragem ocorre a interação entre aquilo que o aluno já sabe com um novo conceito, promovendo a construção de significados. Os novos conceitos são agregados ou incorporados na estrutura cognitiva, transformando-a e disponibilizando "novos" conhecimentos, em um nível mais elevado de especificidade e complexidade, para a realização de novas ancoragens (AUSUBEL; NOVAK; HANESIAN, 1980; AUSUBEL, 2003; MOREIRA; MASINI, 2006; MOREIRA, 1997, 2008a).

$\mathrm{Na}$ Teoria da Aprendizagem Significativa (TAS), os conhecimentos prévios, que servem como apoio para a construção de novos significados é denominado subsunçores (AUSUBEL; NOVAK; HANESIAN, 1980; AUSUBEL, 2003; MOREIRA, 2008a, 2008b, 2011a). Os subsunçores são entidades psicológicas, conhecimentos específicos e estáveis da estrutura cognitiva do aluno que permite, por interação, ancorar novos conhecimentos e ampliar os que serviram de apoio (AUSUBEL, 2003). Os subsunçores não se referem somente a conceitos ou operações compreendidas pelos alunos, mas podem ser concepções, construtos, imagens, proposições já incorporadas, representações ou modelos (MOREIRA, 2011a).

Complementando essa perspectiva, tem-se que

O termo subsunçor vem do verbo subsumir que significa inserir-se, ancorarse, em um todo mais amplo. Mas essa isenção, ou ancoragem, não é uma submissão. É um processo interativo onde os dois conhecimentos se modificam, o novo ganha significado e o subsunçor fica mais rico em significados, mais estável, mais forte. (MOREIRA; MASSONI, 2015, p. 33).

Diante disso, a aprendizagem significativa é continuum, em que os subsunçores ampliam-se e qualificam-se para construir significados de conhecimentos mais específicos e complexos, pois "à medida que a aprendizagem significativa ocorre, conceitos são desenvolvidos, elaborados e diferenciados em decorrência de sucessivas interações" (MASINI; MOREIRA, 1982, p. 21). Sendo assim, "progressivamente o subsunçor vai ficando mais estável, mais diferenciado, mais rico em significados, podendo cada vez mais facilitar novas aprendizagens" (MOREIRA, 2011a, p. 3). Complementando esse entendimento, "uma nova informação adquirida por aprendizagem significativa é armazenada de forma um tanto alterada (como produto de assimilação com conceitos subsunçores) e modifica (diferencia mais) os subsunçores aos quais está ligada" (NOVAK, 1981, p. 10).

Então, "a essência do processo de aprendizagem significativa é que as ideias expressas simbolicamente são relacionadas às informações previamente adquiridas através de uma relação não arbitrária e substantiva (não literal)" (AUSUBEL; NOVAK; HANESIAN, 1980, p. 34). 
As relações da não arbitrariedade e da substantividade são propriedades da tarefa aprendizagem, sendo que: a não arbitrariedade remete-se a considerar os subsunçores dos alunos para promover a interação com os conhecimentos abordados na tarefa de aprendizagem; e a substantividade remete-se a propiciar a compreensão da essência de um conceito, não apenas a memorização de palavras e de números (literal), mas a construção de significados (substantiva) (AUSUBEL; NOVAK; HANESIAN, 1980; NOVAK, 1981; AUSUBEL, 2003).

Essas duas propriedades estão relacionadas, pois a compreensão do conhecimento a construção do significado - ocorre na interação daquilo que o aluno já sabe com a nova informação, ou seja, ambos os conhecimentos se modificam: o novo constrói significado e o prévio qualifica-se, em termos de complexidade, de generalidade e de especificidade (AUSUBEL; NOVAK; HANESIAN, 1980; NOVAK, 1981; AUSUBEL, 2003; MOREIRA, 2008a). Diante disso, o aluno vai organizando e ordenando hierarquicamente esses conhecimentos na sua estrutura cognitiva (AUSUBEL; NOVAK; HANESIAN, 1980; NOVAK, 1981; AUSUBEL, 2003).

Em termos de organização didática das tarefas de aprendizagem, a TAS afirma que "as ideias mais gerais e inclusivas da disciplina devem ser apresentadas no início para, somente então, serem progressivamente diferenciadas em termos de detalhe e especificidade" (MASINI; MOREIRA, 1982, p. 21). Ausubel, Novak e Hanesian (1980, p. 159) justificam essa organização, pois consideram

Esta ordem de apresentação presumivelmente corresponde à sequência natural de aquisição da consciência e sofisticação cognitiva quando os seres humanos são espontaneamente expostos ou a um campo completamente desconhecido do conhecimento ou a um ramo desconhecido de um corpo de conhecimento familiar. Também corresponde ao modo postulado em que este conhecimento é representado, organizado e guardado no sistema cognitivo humano.

No processo de elaboração das tarefas de aprendizagem precisa verificar se o aluno possui subsunçores estáveis e concisos para, então, compreender o conhecimento da tarefa de aprendizagem. Quando os subsunçores não estão disponíveis adequadamente sugere-se a utilização de organizadores prévios para desenvolver os subsunçores necessários e para explicitar a relação que será estabelecida com a tarefa de aprendizagem (MOREIRA, 2011b).

Os organizadores prévios são tarefas disponibilizadas antes da tarefa de aprendizagem, com noções mais inclusivas, abstratas e gerais, auxiliando o estudante a reconhecer conceitos estruturantes e preencher lacunas na estrutura cognitiva que interferem na compreensão de novos significados abordados na tarefa de aprendizagem (MOREIRA, 2011b, 2011c). Os organizadores prévios têm a função "de servir de ponte entre o que o aprendiz já sabe e o que ele deve saber a fim de que o novo material possa ser aprendido de maneira significativa" (MOREIRA, 2011c, p. 40). Essa função didática justifica-se, pois, os organizadores prévios são, geralmente, introduções e/ou sínteses relativamente breves que abordam um conteúdo e a relação com os conhecimentos da tarefa de aprendizagem (AUSUBEL, 2003; MOREIRA, 2011a).

Entretanto, na TAS não é suficiente cuidar somente do planejamento das estratégias didáticas, mas é necessário valorizar o aluno, tornando-o protagonista no processo de aprendizagem. Na aprendizagem significativa, o aluno realiza um esforço mental para relacionar os conhecimentos da sua estrutura cognitiva com os novos presentes na tarefa de 
aprendizagem. Diante disso, o aluno torna-se sujeito ativo no processo de aprendizagem, partindo de conhecimentos prévios constrói-se e reconstroem-se significados, ampliando-os e qualificando-os na estrutura cognitiva. O esforço cognitivo para estabelecer relações e compreender os conhecimentos, guardando-os, ordenando-os e organizando-os na estrutura cognitiva é denominado por predisposição em aprender (AUSUBEL; NOVAK; HANESIAN, 1980; NOVAK, 1981; AUSUBEL, 2003; MOREIRA, 2008a).

A predisposição em aprender é definida como uma disposição "por parte do aprendiz para relacionar uma tarefa de aprendizagem não arbitrariamente e substantivamente a aspectos relevantes de sua estrutura cognitiva" (AUSUBEL; NOVAK; HANESIAN, 1980, p. 523). Desse modo, o esforço cognitivo do aluno é um fator determinante para que a aprendizagem tenda a ser mecânica ou significativa (AUSUBEL; NOVAK; HANESIAN, 1980; NOVAK, 1981; PELIZZARI et al., 2002; AUSUBEL, 2003). A seguir, apresenta-se a estratégia didática para o ensino da função exponencial.

\section{Descrição da estratégia didática sobre função exponencial}

Em busca de propiciar a compreensão dos conceitos e o desenvolvimento de uma aprendizagem significativa sobre função exponencial, elaborou-se uma estratégia didática que será a presentada a seguir. A estratégia didática foi aplicada no último semestre letivo de 2017, tendo duração de 16 períodos de 50 minutos cada um, em turno regular de aula. Os participantes são 21 alunos do primeiro ano do Ensino Médio de uma escola pública do interior do Rio Grande do Sul, na qual a autora principal deste trabalho é a professora da turma.

Em termos didáticos, a estratégia foi dividida em seis etapas, contemplando princípios da TAS. Inicialmente, aplica-se um questionário prévio para verificar e ativar possíveis subsunçores que serão necessários na realização da tarefa de aprendizagem. Na segunda etapa, exploram-se conceitos gerais sobre função exponencial, por meio de uma atividade de dobradura de papel para, posteriormente, na terceira etapa abordar conteúdos mais específicos, tais como: potenciação de um produto; divisão de potências de mesma base; potenciação de potência; potenciação de fração; e potência com expoente negativo. $\mathrm{Na}$ quarta etapa, busca-se estabelecer relações de conhecimentos matemáticos com situações contextualizadas, por meio de uma oficina de jogos, sendo que na quinta etapa abordam-se conceitos mais específicos da função exponencial aplicados em Matemática Financeira. Por fim, aplica-se um novo questionário para coletar indícios das aprendizagens desenvolvidas pelos alunos no decorrer da estratégia didática. A seguir, descrevem-se as seis etapas que foram planejadas e aplicadas aos alunos.

\subsection{Etapa 1 - Questionário prévio (1 período de aula)}

O objetivo desta etapa é verificar e ativar subsunçores para permitir a compreensão dos conteúdos explorados nas próximas etapas da estratégia didática, para isto, aplicou-se um questionário aos alunos, composto das seguintes perguntas (Quadro 1). 
Quadro 1 - Perguntas aplicadas aos alunos participantes da pesquisa.

1) O que é expoente?

2) Qual a forma correta de calcular $2^{3}$ ?

3) Entre as situações a seguir, qual você considera representar uma situação que envolve um cálculo de potência?

4) Em um estacionamento há 4 automóveis, em cada automóvel há 4 rodas e em cada roda há 4 parafusos. Qual potência representa o total de parafusos presentes nessa situação?

Fonte: Elaborado pelos autores.

Essas perguntas visam identificar os conhecimentos gerais que os alunos possuem sobre potência, tais como: os conceitos de expoente e potência e a resolução de cálculos com potências. Essa etapa está em consonância com a TAS, pois "não tem sentido 'começar a ensinar' sem fazer um levantamento, por menor que seja, do conhecimento prévio dos alunos, sem saber 'onde estão' os alunos" (MOREIRA; MASSONI, 2015, p. 36). Diante disso, os resultados dessa etapa são primordiais para o desenvolvimento da estratégia didática.

\subsection{Etapa 2 - Dobradura de papel (2 períodos de aula)}

Nesta etapa é proposta uma atividade para introduzir o conceito de função exponencial, de uma forma prática. A tarefa consistia em dobrar uma folha de papel ao meio, e considerar a quantidade de retângulos encontrados após cada dobra. A partir das dobraduras, os alunos são instigados a preencher uma tabela, conforme ilustra o Quadro 2, mostrando a relação exponencial entre o número de dobras e a quantidade de retângulos formados.

Quadro 2 - Atividade planejada para introduzir o conceito de função exponencial

\begin{tabular}{|c|c|c|c|c|}
\hline \multirow{2}{*}{ Representadas das dobras } & $\begin{array}{c}\text { Número } \\
\text { de } \\
\text { dobras }\end{array}$ & $\begin{array}{c}\text { Quantidade } \\
\text { de } \\
\text { retângulos }\end{array}$ & $\begin{array}{c}\text { Representação } \\
\text { matemática }\end{array}$ & Potência \\
\hline & 0 & 1 & & \\
\hline & 1 & 2 & 2 & $2^{1}$ \\
\cline { 2 - 6 } & 2 & 4 & $2 \cdot 2$ & $2^{2}$ \\
\hline & 3 & 8 & $2 \cdot 2 \cdot 2$ & $2^{3}$ \\
\hline & 4 & 16 & $2 \cdot 2 \cdot 2 \cdot 2$ & $2^{4}$ \\
\hline & $\ldots$ & $\ldots$ & $\ldots$ & $\ldots$ \\
\hline
\end{tabular}

Fonte: Elaborado pelos autores.

Na perspectiva da TAS, essa atividade promove a ação cognitiva do aluno, pois estabelece uma relação entre um subsunçor (o conhecimento de potência) com um conhecimento novo (o conceito de função exponencial) abordado na tarefa de aprendizagem. Desse modo, introduz-se um conceito geral para na próxima atividade explorar conceitos mais específicos sobre a potência e, consequentemente, sobre a função exponencial. 


\subsection{Etapa 3 - Jogo da propriedade de potências ( 3 períodos de aula)}

As propriedades de potenciação são um conhecimento que os alunos, geralmente, compreendem com facilidade no qual se propôs um jogo de revisão conceitual, com o objetivo de retomar as propriedades básicas, ativando subsunçores, que serão necessários para compreender conceitos mais específicos e resolver operações mais complexas. A atividade consistia em uma espécie de jogo da memória (Figura 1), em que é preciso formar os pares corretos, justificando a resposta, com os cálculos.

Figura 1 - Print da tela do jogo das propriedades de potências.

PROPRIEDADES DE POTÊNCIAS

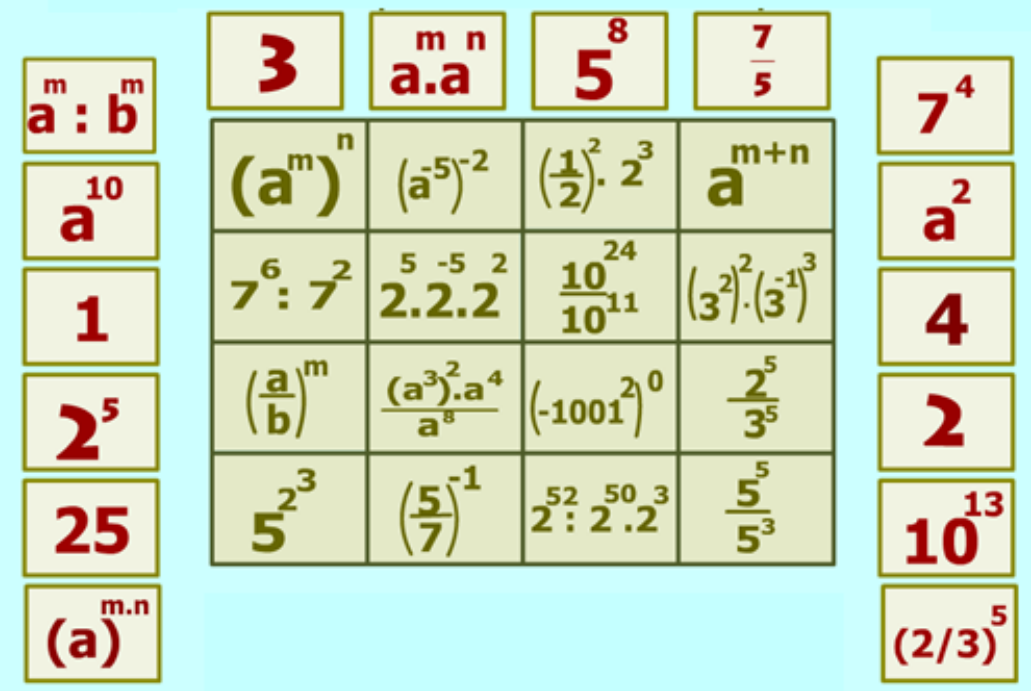

Fonte: Bornatto (2015). Disponível em:

http://objetoseducacionais2.mec.gov.br/bitstream/handle/mec/10486/POT\%C3\%8ACIAS.swf?sequence=1.

Acesso em: 15 ago. 2017.

A Figura 1 mostra a atividade, que inicialmente foi realizada em sala de aula, recortando e colando os pares no caderno, e em seguida, os resultados foram conferidos na atividade online. No jogo online ${ }^{6}$, os quadrinhos das extremidades deveriam ser ligados corretamente às operações dos quadrinhos centrais.

\subsection{Etapa 4 - Oficina de jogos (6 períodos de aula)}

Nesta etapa, relacionaram-se os jogos de Xadrez e Torre de Hanói, observado na Figura 2, com a função exponencial. Para cada atividade, os alunos em grupos jogavam um dos jogos e, posteriormente, foi conversado sobre a lenda de cada jogo e suas relações com as funções exponenciais.

\footnotetext{
${ }^{6}$ Disponível em:

http://objetoseducacionais2.mec.gov.br/bitstream/handle/mec/10486/POT\%C3\%8ACIAS.swf?sequence=1. Acesso em: Acesso em: 15 ago. 2017.
} 
Figura 2 - Representação do tabuleiro de xadrez e da Torre de Hanói
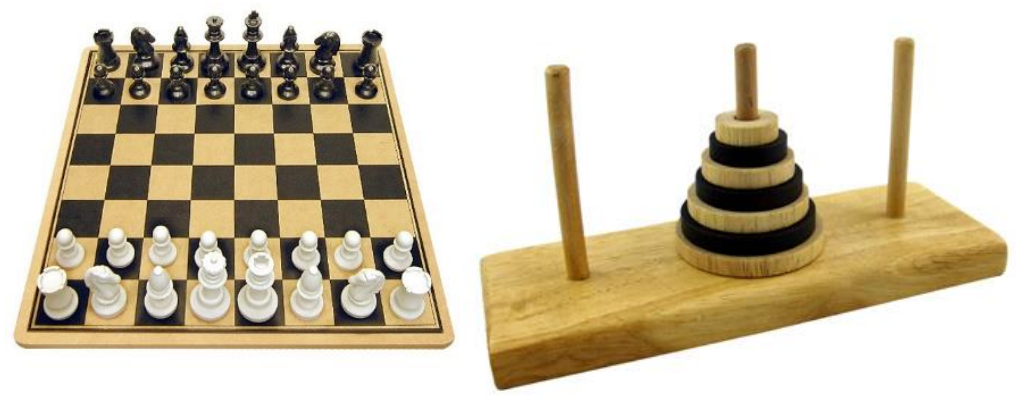

Fonte: Flor (2013). Disponível em: http://importenciadosjogosmatematicos.blogspot.com/. Acesso em: 12 abr. 2018.

O jogo de xadrez, segundo a lenda de sua criação, teria sido um presente para o rei, e o rei, querendo agradecer, ofereceu para o criador o que ele quisesse. $O$ inventor do jogo então, pediu dois grãos de trigo pela primeira casa, quatro grãos de trigo pela segunda casa, oito grãos de trigo pela terceira casa, e assim por diante, até completar as 64 casas. Apesar de ser um pedido simples, o rei constatou que não teria essa quantidade, sendo necessários alguns séculos para produzir esse número de grãos (NEVES, 2009). 0 pedido do criador corresponde a uma sequência exponencial, em que a base é o 2, e o expoente a casa correspondente, conforme consta no Quadro 3.

Quadro 3-Questões sobre Matemática Financeira.

\begin{tabular}{|c|c|c|}
\hline Quantidade de casas do tabuleiro & Potência & Quantidade de grãos \\
\hline 1 & $2^{1}$ & 2 \\
\hline 2 & $2^{2}$ & 4 \\
\hline 3 & $2^{3}$ & 8 \\
\hline 4 & $2^{4}$ & 16 \\
\hline$\ldots$ & $\ldots$ & $\ldots$ \\
\hline 64 & $2^{64}$ & 18.446 .744 .073 .709 .551 .615 \\
\hline
\end{tabular}

Fonte: Elaborado pelos autores.

Em relação a Torre de Hanói, cada quantidade de peças, resulta em jogadas mínimas, e as jogadas são dadas em função de uma potência de base dois elevada a quantidade de peças, e o resultado da potência, menos um, resulta nos movimentos mínimos por jogada. Essas atividades tem o objetivo de mostrar situações reais, as quais se pode aplicar a função exponencial e propiciando a contextualização dos conhecimentos matemáticos (IMÁTICA, 2020).

\subsection{Etapa 5 - Matemática Financeira (4 períodos de aula)}

Nesta etapa, propôs-se uma situação problema sobre juros compostos com o objetivo de estabelecer uma relação da função exponencial com a fórmula do cálculo do montante dos juros compostos. A situação-problema proposta aos estudantes foi a seguinte: "Uma pessoa toma emprestado $\mathrm{R} \$ 1000,00$ para pagar depois de três meses, à taxa de $4 \%$ ao mês no regime de juros compostos. Qual o montante ao final de cada mês?" (RIBEIRO, 2011, p. 186).

Após a resolução da situação-problema, organizou-se a turma para conversar com profissionais que trabalham em uma instituição financeira cooperativa sobre a definição e as 
taxas de juros do crédito pessoal, cheque especial, crédito imobiliário, crédito de veículos e crédito consignado. Com as informações em mãos, debateram-se as formas de empréstimo, e calcularam-se algumas situações para cada tipo de empréstimo (Quadro 4).

Quadro 4-Questões sobre Matemática Financeira.

\begin{tabular}{|c|}
\hline $\begin{array}{l}\text { 1) Se você comprar uma casa, pela Minha Casa, Minha Vida7, e escolher um imóvel de } \\
\mathrm{R} \$ 150.000,00 \text {. Sabendo que a liberação de financiamento em nossa região é de } \\
\mathrm{R} \$ 98.000,00 \text {. Quais as condições que você poderia pagar o financiamento? Leve em } \\
\text { consideração que você tenha dinheiro para cobrir a entrada de } \mathrm{R} \$ 52.000,00 \text {. }\end{array}$ \\
\hline $\begin{array}{l}\text { 2) Se você deseja comprar um carro, no valor de } R \$ 30.000,00 \text {, qual proposta se encaixa } \\
\text { melhor? Como ficam as condições em } 36 \text { meses? }\end{array}$ \\
\hline $\begin{array}{l}\text { 3) Você precisa pagar uma dívida de } \mathrm{R} \$ 2.000,00 \text {. Que condição poderia cobri sua dívida, } \\
\text { para paga-la em um ano? }\end{array}$ \\
\hline
\end{tabular}

Fonte: Elaborado pelos autores.

\subsection{Etapa 6 - Questionário final (1 período de aula)}

Esta atividade tem o propósito de realizar uma avaliação da estratégia didática, na perspectiva dos alunos, e verificação de quais situações os alunos reconhecem que envolvem conhecimentos sobre a função exponencial. Os alunos responderam um questionário misto, composto por três questões que abordavam sobre: a participação do aluno durante as atividades; situações em que se encontram aplicações da função exponencial; e se estratégia didática possibilitou a contextualização do ensino, facilitando a compreensão dos conhecimentos matemáticos (Quadro 5).

Quadro 5-Questionário final aplicado aos alunos.

1) Sobre a proposta de ensino das funções exponenciais:

( ) Você participou ativamente e compreendeu os conceitos propostos;

( ) Você participou parcialmente e compreendeu os conceitos propostos;

( ) Você participou parcialmente e compreendeu parcialmente os conceitos propostos;

( ) Você participou parcialmente e não compreendeu os conceitos propostos.

( ) Você não participou e não compreendeu os conceitos propostos.

2) Cite alguns exemplos de onde podemos encontrar a função exponencial.

3) Você acredita que está proposta foi significativa:

( ) Sim, pois compreendi situações reais de aplicabilidade da função exponencial.

( ) Sim, mas não me interessou a proposta.

( ) Não, pois não me interessou a proposta.

Fonte: Elaborado pelos autores.

\footnotetext{
7 “É uma iniciativa do Governo Federal que oferece condições atrativas para o financiamento de moradias nas áreas urbanas para famílias com renda familiar bruta de até $\mathrm{R} \$ 7.000,00$ por mês. Em parceria com estados, municípios, empresas e entidades sem fins lucrativos, o programa vem mudando a vida de milhares de famílias brasileiras." (BRASIL, 2020).
} 
A seguir, apresentam-se os resultados do questionário prévio e do questionário final, bem como a percepção do envolvimento dos alunos na execução das atividades propostas na estratégia didática.

\section{Resultados da aplicação da estratégia didática}

Em relação ao questionário prévio, cujo objetivo foi identificar os conhecimentos prévios dos alunos sobre potência, os resultados mostram que todos reconheciam e sabiam efetuar uma potência na forma algébrica. Desses, $71 \%$ souberam identificar conhecimentos que envolviam a potência em uma situação-problema, e $29 \%$ não souberam. A partir desses dados, constatou-se que os alunos teriam subsunçores para realizarem as etapas previstas na estratégia didática, ancorando novos conhecimentos na sua estrutura cognitiva.

Na Etapa 2, na atividade de dobradura, os alunos receberam uma folha de papel e foram questionados: Qual forma geométrica representa a folha? e Como é possivel encontrar mais retângulos? Os alunos reconhecerem que a dobradura poderia ser uma estratégia para determinar mais retângulos na folha. Diante disso, decidiu-se registrar no quadro a relação entre a quantidade de dobras com a de retângulos formados. Na terceira dobradura, os alunos deram o palpite que a quantidade de retângulos seria seis, pois inicialmente multiplicavam a quantidade de retângulos pela quantidade de dobras. Ao dobrar a folha pela terceira vez, foi interessante a reação dos alunos, ao se darem conta que na verdade eram oito retângulos, e que deveriam dobrar a quantidade de retângulos.

Após alguns registros no quadro, os alunos foram questionados: $O$ que perceberam nessa lista? Como se pode expressar a quantidade de retângulos em relação ao número de dobras? Com o auxílio da professora, os alunos perceberam a existência de relação exponencial entre as variáveis, sendo que: a base da função exponencial é o número dois; o expoente representa a variável independente que é a quantidade de dobras de cada etapa; e a variável dependente é a quantidade de retângulos. Além disso, nessa situação pode-se explorar e exemplificar a propriedade que qualquer número elevado ao expoente zero é um.

$\mathrm{Na}$ Etapa 3, os alunos foram divididos em grupos, para que compartilhassem conhecimentos, e realizaram o jogo de memória das operações com as propriedades de potências. Os alunos tiveram dificuldade em recordar as propriedades, assim a professora, como mediadora, auxiliou-os com algumas dúvidas, explicando os conhecimentos matemáticos envolvidos na atividade. Desse modo, buscou-se construir significados para que os alunos possam compreender os conhecimentos mais específicos sobre a função exponencial.

$\mathrm{Na}$ Etapa 4, os alunos se mostraram interessados e envolveram ativamente na realização das atividades propostas na oficina dos jogos. Novamente, visando o compartilhamento de conhecimentos e o desenvolvimento de aprendizagens, a turma foi separada em grupos. Durante o jogo da Torre de Hanói solicitou-se o registro da quantidade de movimentos de acordo com a quantidade de peças, como mostra a Figura 3 a seguir: 


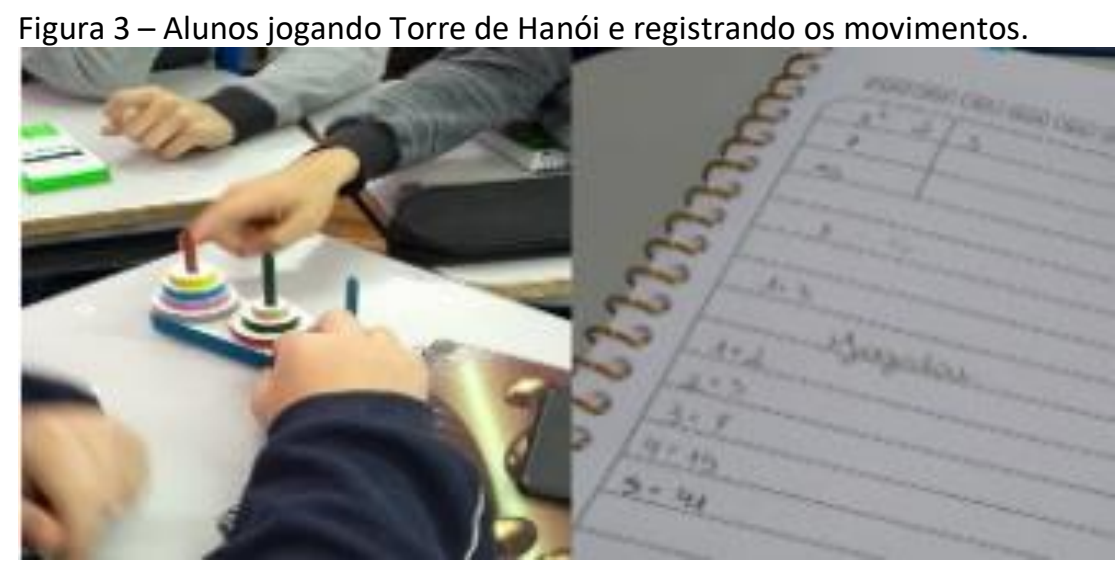

Fonte: Elaborado pelos autores.

Após os registros de algumas jogadas na Torre de Hanói, os alunos disponibilizaram as jogadas mínimas para concluir os desafios e os alunos foram questionados: Como se pode representar matematicamente essa relação? Alguns alunos notaram que se acrescentassem uma unidade em cada jogada mínima, se teria a mesma sequência dos registros da atividade da Etapa 2. Desse modo, os alunos constataram uma função exponencial que permite determinar a quantidade de movimentos mínimos a partir da quantidade de peças utilizadas.

$\mathrm{Na}$ Etapa 5, os alunos foram levados até uma instituição financeira cooperativa de crédito para tirarem dúvidas e conhecerem sobre o mercado financeiro, principalmente sobre as taxas de investimentos e empréstimos. Nesta instituição financeira, as taxas variam conforme os produtos adquiridos e a renda de cada associado (cliente). A partir disso, o professor e os alunos definiram um valor médio das taxas cobradas pela instituição para, posteriormente, resolverem algumas situações-problema, como por exemplo: uma simulação dos juros cobrados do empréstimo de $\mathbf{\$} \$ 98.000,00$ pelo Programa Minha Casa, Minha Vida. Nessa atividade, os alunos ficaram surpresos com o valor cobrado de juros, reconhecendo a importância de se organizar e economizar dinheiro para depois fazer um investimento, ou diminuir o valor do empréstimo.

Na Etapa 6, a aplicação do questionário para avaliar a estratégia didática, os resultados mostram que a maioria dos alunos se envolvem durante as atividades e que compreenderam os conhecimentos matemáticos, sendo que: $30 \%$ dos alunos relataram que participaram ativamente e compreenderam os conceitos propostos; $45 \%$ participaram parcialmente e compreenderam os conceitos propostos; $20 \%$ participaram parcialmente e compreenderam parcialmente os conceitos propostos; e $5 \%$ participaram parcialmente e não compreenderem os conceitos propostos.

Outra questão que verificava se a estratégia foi interessante, na perspectiva dos alunos, e se promoveu a compreensão de situações em que os conhecimentos de função exponencial são aplicados teve-se que $80 \%$ consideraram que a estratégia didática foi interessante e possibilitou a compreensão de situações reais que a função exponencial é aplicada, outros $15 \%$ perceberam a aplicação da função exponencial, mas não gostaram da estratégia didática e $5 \%$ disseram que a estratégia didática não os interessou. Em virtude do tempo disponível para a aplicação da estratégia didática não se tomou nenhuma atitude em relação aos alunos insatisfeitos. Uma atitude que poderia ser tomada consiste em conversar com eles e buscar fazer uma ligação do conteúdo com algo do seu interesse ou ainda planejar outras estratégias didáticas. Essa ação é necessária, pois Ausubel (2003) compreende que a 
aprendizagem significativa ocorre quando os alunos estão predispostos em aprender, ou seja, estão envolvidos na realização das atividades e querem realizar um esforço mental para estabelecer relações entre conhecimentos.

Em relação ao reconhecimento das situações em que a função exponencial é aplicada, as respostas dos alunos foram organizadas num arquivo de texto e depois fragmentadas, realizando um procedimento de categorização similar ao método de Análise Conteúdo de Bardin (2011), totalizando 45 fragmentos que foram agrupados por semelhanças. A partir dos fragmentos agrupados estabeleceram-se duas categorias que representam as respostas dos alunos: Aplicação em jogos e Aplicação no mercado financeiro.

A categoria Aplicação em jogos é composta por sete fragmentos, reconhecendo que a função exponencial está presente na origem do jogo de xadrez e na Torre de Hanói. A categoria Aplicação no mercado financeiro é composta 38 fragmentos, conforme consta no Quadro 6.

Quadro 6 - Fragmentos da categoria Aplicação no mercado financeiro e suas quantidades.

\begin{tabular}{|c|c|}
\hline Fragmento & Frequência absoluta \\
\hline $\begin{array}{c}\text { Identificaram que conhecimentos sobre função exponencial } \\
\text { estão presentes na solicitação de empréstimos, pois os juros } \\
\text { pagos na instituição financeira crescem exponencialmente. }\end{array}$ & 21 alunos \\
\hline $\begin{array}{c}\text { Identificaram que conhecimentos sobre função exponencial } \\
\text { estão presentes nos juros pagos ao comprar um objeto em } \\
\text { alguma loja. }\end{array}$ & 9 alunos \\
\hline $\begin{array}{c}\text { Identificaram que conhecimentos sobre função exponencial } \\
\text { estão presentes nos juros gerados na poupança ou na } \\
\text { aplicação de dinheiro em uma instituição financeira. }\end{array}$ & 2 alunos \\
\hline $\begin{array}{c}\text { Identificaram que conhecimentos sobre função exponencial } \\
\text { estão presentes na matemática financeira. }\end{array}$ & 6 . \\
\hline
\end{tabular}

Fonte: Elaborado pelos autores.

Observa-se que os alunos conseguiram estabelecer diferentes relações entre as situações reais com o conteúdo matemático, sendo que algumas relações não foram abordadas na estratégia didática.

Portanto, tem-se a perspectiva que a estratégia didática aplicada no Ensino Médio atingiu seu objetivo, pois $80 \%$ dos alunos afirmaram e demonstraram durante as atividades que compreenderam os conceitos e as propriedades sobre a função exponencial. A estratégia didática tornou o aluno protagonista no processo de aprendizagem, na qual utilizou seus conhecimentos prévios para compreender conceitos mais específicos. Além disso, as atividades propostas instigaram o envolvimento do aluno, sendo notável seu esforço mental - a predisposição em aprender - para estabelecer relações entre os conhecimentos e os conteúdos abordados na estratégia didática. Assim, apresentam-se indícios de ter ocorrido uma aprendizagem significativa dos conceitos sobre a função exponencial, pois se atingiu a concepção de aprendizagem de Moreira e Massoni (2015, p. 30) que relataram que "aprendemos a partir do que já sabemos e aprendemos se queremos". 


\section{Considerações finais}

A partir da descrição dos resultados constatou-se que o objetivo de compartilhar uma estratégia didática que torna o aluno protagonista no processo de aprendizagem de conceitos e propriedades das funções exponenciais foi atingido neste trabalho. A estratégia didática foi aplicada em uma turma de primeiro no ano do Ensino Médio, no qual se verificou que $80 \%$ dos alunos compreenderam a função exponencial e associaram-na com situações reais. Ausubel (2003) defende em sua teoria que para que o processo de aprendizagem significativa ocorra o professor precisa oferecer estratégias significativas, e o aluno precisa estar predisposto a aprender.

A utilização de diferentes estratégias de ensino possibilitou a interação dos alunos com diferentes recursos de aprendizagem, rompendo um ensino descontextualizado e meramente expositivo para promover a interação, a cooperação e compartilhamento de conhecimentos entre os colegas e com o professor. Devido às atividades planejadas, a maioria dos alunos, $80 \%$, envolveu-se na execução das etapas da estratégia didática, sendo um forte indicativo da predisposição para aprender os conceitos de função exponencial.

Portanto, tem a perspectiva que essa estratégia didática possa ser desenvolvida e aprimorada por outros professores, visando qualificar os processos de ensino e de aprendizagem no Ensino Médio. O planejamento deste trabalho requisitou dedicação e paciência, para incorporar diferentes atividades - dobraduras, recurso da web, oficina de jogos e situações-problemas com matemática financeira - na estratégia didática. Apesar do trabalho de planejar as etapas dessa estratégia didática, os resultados foram gratificantes e motivadores, pois se teve vários indícios que os alunos reconheceram a utilidade ou a aplicabilidade da função exponencial no mundo real e construíram significados dos conhecimentos matemáticos abordados.

\section{Referências}

AUSUBEL, David. P. Aquisição e retenção de conhecimento: uma perspectiva cognitiva. Lisboa: Paralelo, 2003.

AUSUBEL, David. P.; NOVAK, Joseph D.; HANESIAN, Helen. Psicologia Educacional. 2. ed. Rio de Janeiro: Interamericana, 1980.

BARDIN, Laurence. Análise de conteúdo. São Paulo: Edições 70, 2011.

BOOTH, Ivete Ana Schmitz et al. Aprendizagem baseada em problemas: Estudantes de ensino médio atuando em contexto de ciência e tecnologia. Brasília: Abenge, 2016.

BORNATTO, G. Propriedade de potências. [S.I.], 2015. Disponível em: http://objetoseducacionais2.mec.gov.br/bitstream/handle/mec/10486/POT\%C3\%8ACIAS.swf?seque nce=1. Acesso em: 15 ago. 2017.

BRASIL. Minha Casa Minha Vida - Habitação Urbana. [S.I.], 2020. Disponível em: https://www.caixa.gov.br/voce/habitacao/minha-casa-minha-vida/urbana/Paginas/default.aspx. Acesso em: 20 set. 2020.

D’ AMBROSIO, Ubiratan. Educação matemática da teoria à prática. 22. ed. Campinas-SP, Papirus, 2011. 
D’ AMBROSIO, Ubiratan. Transdisciplinaridade. São Paulo: Palas Athena, 1997.

DAVID P. AUSUBEL. Home. Disponível em: http://www.davidausubel.org/index.html. Acesso em: 05 mar. 2019.

DEMO, Pedro. Educar pela pesquisa. 9. ed. Campinas: Autores Associados, 2011.

FLOR, A. C. A matemática por trás dos jogos. [S.I.], 2013. Disponível em:

http://importenciadosjogosmatematicos.blogspot.com/. Acesso em: 12 abr. 2018.

GALIAZZI, Maria do Carmo. Educar pela pesquisa: ambiente de formação de professores de ciências. Ed. Unijuí, 2003.

IMÁTICA. Torres de Hanói. [S.I.], 2020. Disponível em:

http://www.matematica.br/programas/hanoi/ihanoi7.html. Acesso em: 20 set. 2020.

MASINI, Elcie Aparecida Fortes Salzano; MOREIRA, Marco Antônio. Aprendizagem significativa: a teoria de David Ausubel. São Paulo: Moraes, 1982.

MOREIRA, Marco Antônio. Aprendizaje significativo: un concepto subyacente. In: ENCUENTRO INTERNACIONAL SOBRE EL APRENDIZAJE SIGNIFICATIVO, 2., 1997, Burgos. Actas... Burgos (Espanha), 1997.

MOREIRA, Marco Antônio. A teoria da Aprendizagem Significativa segundo Ausubel. IN: MASINI, Elcie Aparecida Fortes Salzano; MOREIRA, Marco Antônio (Org.). Aprendizagem significativa: condições para ocorrência e lacunas que levam a comprometimentos. São Paulo: Vetor, 2008 a.

MOREIRA, Marco Antônio. Organizadores previos y aprendizaje significativo. Revista Chilena de Educación Científica, v. 7, n. 2, p. 23-30, 2008b. Disponível em: https://www.if.ufrgs.br/ moreira/ORGANIZADORESesp.pdf. Acesso em: 14 jan. 2019.

MOREIRA, Marco Antônio. O que é afinal aprendizagem significativa. In: MOREIRA, Marco Antônio Aprendizagem significativa: a teoria e textos complementares. São Paulo: Livraria de Física, 2011a.

MOREIRA, Marco Antônio. Unidades de enseñanza potencialmente significativas - UEPS.

Aprendizagem Significativa em Revista/Meaningful Learning Review, Rio Grande do Sul, v. 1, n. 2, p. 43-63, 2011b. Disponível em: http://www.if.ufrgs.br/asr/artigos/Artigo_ID10/v1_n2_a2011.pdf. Acesso em: 14 jan. 2019.

MOREIRA, Marco Antônio. Aprendizagem significativa: um conceito subjacente. Porto Alegre, 2011c. Disponivel em: http://www.if.ufrgs.br/ moreira/apsigsubport.pdf. Acesso em: 15 ago. 2017

MOREIRA, Marco Antônio; MASINI, Elcie Aparecida Fortes Salzano. Aprendizagem significativa: a teoria de David Ausubel. 2. ed. São Paulo: Centauro, 2006.

MOREIRA, Marco Antônio; MASSONI, Neusa Teresinha. Textos de apoio ao professor de Física. Porto Alegre: UFRGS, 2015.

NEVES, Rodrigo. Agregando Conhecimentos. [S.I.], 2009. Disponível em:

https://sites.google.com/site/professorrodrigoneves/recados/agregandoconhecimentos. Acesso em: 20 set. 2020. 
NOVAK, Joseph D. Uma teoria de educação. São Paulo: Pioneira, 1981.

PACHECO, Marina Buzin; ANDREIS, Greice da Silva Lorenzzetti. Causas das dificuldades de aprendizagem em Matemática: percepção de professores e estudantes do 3o ano do Ensino Médio. Revista Principia - Divulgação Científica e Tecnológica do IFPB, [S.I.], n. 38, fev. 2018. Disponível em: https://periodicos.ifpb.edu.br/index.php/principia/article/view/1612. Acesso em: 14 set. 2020.

PELIZZARI, Adriana et al. Teoria da aprendizagem significativa segundo Ausubel. Revista PEC, Curitiba, v. 2, n. 1, p. 37-42, 2002.

PONTES, Edel Alexandre Silva. 1110 ato de ensinar do professor de matemática na educação básica. Ensaios Pedagógicos, v. 2, n. 2, mai.-ago. 2018. Disponível em: http://www.ensaiospedagogicos.ufscar.br/index.php/ENP/article/view/76/107. Acesso em: 14 set. 2020.

RIBEIRO, Jackson. Ciência, Linguagem e Tecnologia Matemática. São Paulo: Scipione, 2011.

SANTOS, M. B. Por que devo aprender "estas coisas"? Revista Mundo Jovem. Porto Alegre, 2004.

SILVA, João Batista da; SALES, Gilvandenys Leite; CASTRO, Juscileide Braga de. Gamificação como estratégia de aprendizagem ativa no ensino de Física. Revista Brasileira de Ensino de Física, v. 41, n. 4, 2019. Disponível em: https://www.scielo.br/pdf/rbef/v41n4/1806-9126-RBEF-41-4e20180309.pdf. Acesso em: 14 set. 2020.

SOARES, Eliana Maria do Sacramento; SAUER, Laurete Zanol. Um novo olhar sobre a aprendizagem de matemática para a engenharia. In: CURY, Helena Noronha. (Org.). Disciplinas matemáticas em cursos superiores. Porto Alegre: EDIPUCRS, 2004.

VARRIALE, Maria Cristina; TREVISAN, Vilmar. Novos Conteúdos e Novas Abordagens. In: BÚRIGO, Elisabete Z. et al. (Org.). A matemática na escola: novos conteúdos, novas abordagens. Porto Alegre: Ed. UFRGS, 2012. 